\title{
Loss of receptor-mediated lipid uptake via scavenger receptor A or CD36 pathways does not ameliorate atherosclerosis in hyperlipidemic mice
}

\author{
Kathryn J. Moore, ${ }^{1}$ Vidya V. Kunjathoor, ${ }^{1}$ Stephanie L. Koehn, ${ }^{1}$ Jennifer J. Manning, ${ }^{1}$ \\ Anita A. Tseng, ${ }^{1}$ Jessica M. Silver, ${ }^{1}$ Mary McKee,${ }^{2}$ and Mason W. Freeman' \\ ${ }_{1}^{1}$ Lipid Metabolism Unit and 2Program in Membrane Biology and Renal Unit, Massachusetts General Hospital, \\ Harvard Medical School, Boston, Massachusetts, USA.
}

\begin{abstract}
Macrophage internalization of modified lipoproteins is thought to play a critical role in the initiation of atherogenesis. Two scavenger receptors, scavenger receptor A (SR-A) and CD36, have been centrally implicated in this lipid uptake process. Previous studies showed that these receptors mediated the majority of cholesterol ester accumulation in macrophages exposed to oxidized LDL and that mice with deletions of either receptor exhibited marked reductions in atherosclerosis. This work has contributed to an atherosclerosis paradigm: scavenger receptor-mediated oxidized lipoprotein uptake is required for foam cell formation and atherogenesis. In this study, $A_{p o e^{-/}}$mice lacking SR-A or CD36, backcrossed into the C57BL/6 strain for 7 generations, were fed an atherogenic diet for 8 weeks. Hyperlipidemic $\mathrm{Cd}_{36} \mathrm{~F}^{-/} \mathrm{Apoe}^{-/-}$and $\mathrm{Msr1}^{-/-} \mathrm{Apoe}^{-/-}$mice showed significant reductions in peritoneal macrophage lipid accumulation in vivo; however, in contrast with previous reports, this was associated with increased aortic sinus lesion areas. Characterization of aortic sinus lesions by electron microscopy and immunohistochemistry showed abundant macrophage foam cells, indicating that lipid uptake by intimal macrophages occurs in the absence of CD36 or SR-A. These data show that alternative lipid uptake mechanisms may contribute to macrophage cholesterol ester accumulation in vivo and suggest that the roles of SR-A and CD36 as proatherosclerotic mediators of modified LDL uptake in vivo need to be reassessed.
\end{abstract}

\section{Introduction}

Decades of animal and human research have established that hyperlipidemic atherosclerosis arises as a consequence of the deposition and retention of serum lipoproteins in the artery wall. The identification of high affinity, scavenger receptor-uptake pathways that bind modified forms of LDL (1-3) coupled with the finding that the majority of lipid-engorged foam cells in atherosclerotic lesions represent macrophages expressing these receptors (4) led to the hypothesis that receptor-mediated uptake of lipoproteins was a requisite event in the pathogenesis of atherosclerosis. With the advent of the lipid oxidation hypothesis in the 1980s and the molecular identification and cloning of macrophage scavenger receptors in the 1990s, a compelling hypothesis emerged that proposed that the binding of oxidized LDL by one or both of the best characterized scavenger receptors, scavenger receptor A (SR-A) and CD36, initiates foam cell formation and atherogenesis. To validate this hypothesis, several laboratories undertook experiments in mice in which these macrophage scavenger receptor pathways were inactivated by homologous recombination. Many of these studies, though not all, suggested that deletion of the gene locus that codes for SRA-I and SRA-II (Msr1) or deletion of Cd36 in hyperlipidemic mouse models substantially decreased aortic sinus ath-

Nonstandard abbreviations used: FPLC, fast performance liquid chromatography; GC-MS, gas chromatography-mass spectrometry; SR-A, scavenger receptor A. Conflict of interest: The authors have declared that no conflict of interest exists.

Citation for this article: J. Clin. Invest. 115:2192-2201 (2005).

doi:10.1172/JCI24061. erosclerosis and arterial lipid accumulation (5-9). These findings led to the adoption of the dominant paradigm in the field, which posits that uptake of oxidized LDL SR-A and CD36 constitutes the major pathways for foam cell formation in vivo and that lipid uptake by either receptor is a proatherosclerotic event.

Despite the dominance of the scavenger receptor paradigm, there is considerable evidence showing that LDL-derived lipids can enter macrophages via other pathways. As outlined in the original response-to-retention hypothesis formulated by Williams and Tabas $(10,11)$, serum lipoproteins accumulate in the arterial intima where a variety of modifications, including but not limited to oxidation, can alter their structure and enhance their uptake by recruited macrophages. While monomeric LDL appears to require oxidation or acetylation to become a high-affinity ligand for the scavenger receptors, modifications induced by enzymes (e.g., sphingomyelinase, phospholipase C, or secretory phospholipase A2) can lead to increased retention of lipoproteins by matrix proteoglycans and aggregation into large macromolecular complexes that are internalized by non-scavenger receptor-mediated pathways, such as phagocytic, patocytic, or pinocytic uptake mechanisms (reviewed in ref. 12). Furthermore, Kruth and colleagues have reported that native LDL can also be internalized via macropinocytosis of extracellular fluid (13). Measurements of LDL concentrations in human atheroma have detected LDL levels twice those found in the corresponding patients' serum, indicating that the concentration of LDL present in the intima substantially exceeds the concentration of oxidized LDL that saturates the scavenger receptors $(14,15)$. Thus, the amount of lipid available to 


\section{Table 1}

Serum cholesterol and triglyceride levels in $\mathrm{Apoe}^{--}$, Apoe/Cd36--, and $A p o e / M s r 1^{-1-}$ mice after 8 weeks on the Western diet

\begin{tabular}{|c|c|c|c|c|}
\hline Genotype & $n$ & $\begin{array}{l}\text { Total cholesterol } \\
(\mathrm{mg} / \mathrm{dl})^{\mathrm{A}}\end{array}$ & $n$ & $\begin{array}{c}\text { Triglyceride } \\
(\mathrm{mg} / \mathrm{dl})^{\mathrm{A}}\end{array}$ \\
\hline \multicolumn{5}{|l|}{ Male } \\
\hline Apoe ${ }^{-/-}$ & 17 & $922 \pm 220$ & 14 & $116 \pm 20$ \\
\hline Cd36- $6^{-/}$Apoe $e^{-/}$ & 11 & $1,303 \pm 288^{B}$ & 11 & $136 \pm 29$ \\
\hline$M s r 1^{-1-} \mathrm{Apoe}^{-/-}$ & 11 & $1,265 \pm 197^{B}$ & 11 & $86 \pm 19^{B}$ \\
\hline \multicolumn{5}{|l|}{ Female } \\
\hline $\begin{array}{l}\text { Apoe } \\
\text { Cd36- }\end{array}$ & 11 & $1,224 \pm 242$ & 11 & $173 \pm 30^{c}$ \\
\hline Msr1--/-Apoe ${ }^{-/-}$ & 10 & $1,267 \pm 289$ & 6 & $120 \pm 56$ \\
\hline
\end{tabular}

AValues are mean $\pm \mathrm{SD} .{ }^{\mathrm{B} P}<0.005 ;{ }^{C} P<0.05$, as compared with Apoe- ${ }^{-1}$ by ANOVA.

generate macrophage foam cells by non-scavenger receptor-mediated pathways might far exceed that which could be internalized by scavenger receptors.

To further explore the issue of macrophage scavenger receptor involvement in foam cell formation and atherosclerosis, we undertook the generation of mice lacking both SR-A and CD36. Macrophages taken from these mice were isolated and shown to have profound impairment of the ability to take up either oxidized or acetylated LDL generated by standard in vitro techniques for modifying lipoproteins (16). The degree to which in vitro preparations of modified lipoproteins mimic in vivo lipoproteins is unknown, so it was important to demonstrate the impact of scavenger receptor deletion on foam cell formation in animals. Our hypothesis was that if we could establish that SR-A and CD36 did indeed represent the critical uptake mechanisms for macrophage lipid accumulation in vivo, we could directly test the relevance of foam cell formation to atherogenesis by creating mice incapable of making foam cells. In the course of generating animals that lacked apoE and both scavenger receptors, we initially performed studies in mice lacking either SR-A or CD36 and found that we could not replicate previous studies that had shown a reduction in atherosclerosis in $\mathrm{Cd}_{3} 6^{-/-} \mathrm{Apoe}^{-/-}$and $\mathrm{Msr1}^{-/-} \mathrm{Apoe}^{-/-}$mice. Our mice showed increased aortic sinus atherosclerotic lesion area as compared with that of Apoe $e^{-/}$mice despite reductions in peritoneal macrophage cholesterol ester accumulation in vivo. We also found that mice lacking SR-A or CD36 produced an abundance of foam cells in the aortic intima and that the ability of their macrophages to internalize large quantities of aggregated LDL was not reduced by the loss of scavenger receptor expression. These studies call into question the atherosclerosis benefit of deleting either Cd36 or Msr1 in the Apoe-/- mouse model and also suggest that the role of scavenger receptors in mediating in vivo foam cell formation needs reconsideration.

\section{Results}

To assess the impact of loss of scavenger receptor-mediated lipid uptake on atherosclerosis, $\mathrm{Msr}^{-1-} \mathrm{Apoe}^{-/}, \mathrm{Cd} 36^{-/} \mathrm{Apoe}^{-/-}$, and control $\mathrm{Apoe}^{-/-}$mice were fed a Western-style diet for 8 weeks. Apoe ${ }^{-/-}$ mice with targeted deletions in $M s r 1$ or $C d 36$ had significantly higher total serum cholesterol when fed the Western-style diet than mice lacking Apoe alone (Table 1). Mean cholesterol levels in $\mathrm{Msrl}^{-/-} \mathrm{Apoe}^{-/-}(1,265 \pm 197 \mathrm{mg} / \mathrm{dl})$ and $\mathrm{Cd}^{2} 6^{-/-} \mathrm{Apoe}^{-/-}(1303 \pm 288$ $\mathrm{mg} / \mathrm{dl})$ male mice were $40 \%$ greater than those of $\mathrm{Apoe}^{-/-}$counterparts $(922 \pm 220 \mathrm{mg} / \mathrm{dl})$. Female mice lacking Msr1 or Cd36 showed a more modest $20 \%$ increase in serum cholesterol that was not statistically significant. Fast-performance liquid chromatography (FPLC) analysis showed that the increased cholesterol in both the $\mathrm{Msr1}^{-/-} \mathrm{Apoe}^{-/-}$and $\mathrm{Cd} 3 \mathrm{6}^{-/-} \mathrm{Apoe^{-/ }}$ mice was not associated with any redistribution of cholesterol across the various lipoprotein fractions (Figure 1). Previously, Febbraio et al. showed that female

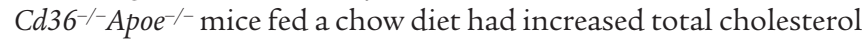
levels when compared with $A p o e^{-/-}$mice, but when both types of mice were fed the same high-fat/high-cholesterol diet used in this study, no differences in plasma cholesterol levels were noted (8). In that study, the mean plasma cholesterol level of the Apoe-/- male mice was $935 \mathrm{mg} / \mathrm{dl}$, which corresponds well with the value $(922$ $\mathrm{mg} / \mathrm{dl}$ ) we measured in the Apoe $e^{-/-}$mice used in our study. Two studies have also noted that Msr 1 expression alters total cholesterol levels in the Apoe ${ }^{-/}$mouse model; Suzuki et al. showed that loss of Msr led to a $40 \%$ increase in total cholesterol while Van Eck et al. demonstrated that overexpression of Msr1 reduced total cholesterol by a similar fraction $(9,17)$. In addition, using SR-A transgenic mice, Wolle et al. showed that overexpression of this receptor suppressed diet-induced increases in lipoproteins that contain apoB (18). Taken together, these data suggest that expression of SR-A and CD36 may contribute to the regulation of circulating cholesterol levels in the hyperlipidemic Apoe $e^{-/}$mouse model.

Despite the $40 \%$ increase in total serum cholesterol observed in male $\mathrm{Msr}^{-/-} \mathrm{Apoe}^{-/-}$and $\mathrm{Cd} 36^{-/-} \mathrm{Apoe}^{-/-}$mice, peritoneal macrophages elicited from these animals showed a significant reduction in cholesterol and cholesterol ester accumulation (Table 2). Gas chromatography-mass spectrometry (GC-MS) analysis revealed a $40-60 \%$ reduction in cellular cholesterol and a corresponding $70-80 \%$ reduction in cholesterol ester in macrophages taken from male $\mathrm{Msr}^{-/-} \mathrm{Apoe}^{-/-}$and $\mathrm{Cd} 36^{-/-} \mathrm{Apoe}^{-/-}$mice as compared with those from control $A p o e^{-/-}$male mice. Surprisingly, no significant differences in macrophage cholesterol and cholesterol ester content were observed in female $\mathrm{Msr}^{-/-} \mathrm{Apoe}^{-/-}$and $\mathrm{Cd}_{3} \mathrm{G}^{-/-} \mathrm{Apoe}^{-/-}$mice when compared with sex-matched controls lacking only Apoe. The reason for this difference between sexes is unclear; however, macrophages derived from male mice consistently showed 2 -fold or greater cholesterol ester levels than did those from female mice despite similar total serum cholesterol levels in male and female mice of each genotype.

Despite the reduction in peritoneal macrophage in vivo foam cell formation observed in male mice lacking $M s r 1$ or $C d 36$, these mice showed increases in aortic sinus atherosclerosis (Figure 2). Cross-sectional analysis revealed $40 \%$ greater lesion area in both male $\mathrm{Msr}^{-1-}$ Apoe $e^{-/-}$and male $\mathrm{Cd}_{3} 6^{-/} \mathrm{Apoe}^{-/-}$mice than in control Apoe ${ }^{-/}$mice (Msr1 ${ }^{-/} \mathrm{Apoe}^{-/}, 252,447 \pm 74,658$; $\mathrm{Cd}_{3} 6^{-/-} \mathrm{Apoe}^{-/-}, 242,222 \pm 79,908$; and $\left.A p o e^{-/}, 149,843 \pm 63,434\right)$, although greater variability in the measurement of the $\mathrm{Cd} 36^{-/} \mathrm{Apoe}^{-/}$lesions prevented this difference from reaching statistical significance $(P=0.087$; Figure 2 , A and $\mathrm{B})$. Significantly larger aortic sinus lesions were also observed in female Apoe ${ }^{-/-}$mice lacking $C d 36$. These mice demonstrated a 20\% increase in mean lesion area as compared with female $\mathrm{Apoe}^{-/-}$control mice $(447,633 \pm 36,168$ vs. $371,417 \pm 80,150)$. Mean lesion area in the Msr1 ${ }^{-/-}$Apoe $e^{-/-}$female mice $(307,339 \pm 52,553)$ was moderately lower than that observed in the controls, but this was not statistically significant. The differences in lesion area paralleled the percentage increases observed in total serum cholesterol in both $\mathrm{Msr}^{1-/-} \mathrm{Apoe}^{-/-}$ and $\mathrm{Cd}_{36^{-/}} \mathrm{Apoe}^{-/-}$mice. These data indicate that loss of Msr1 or 

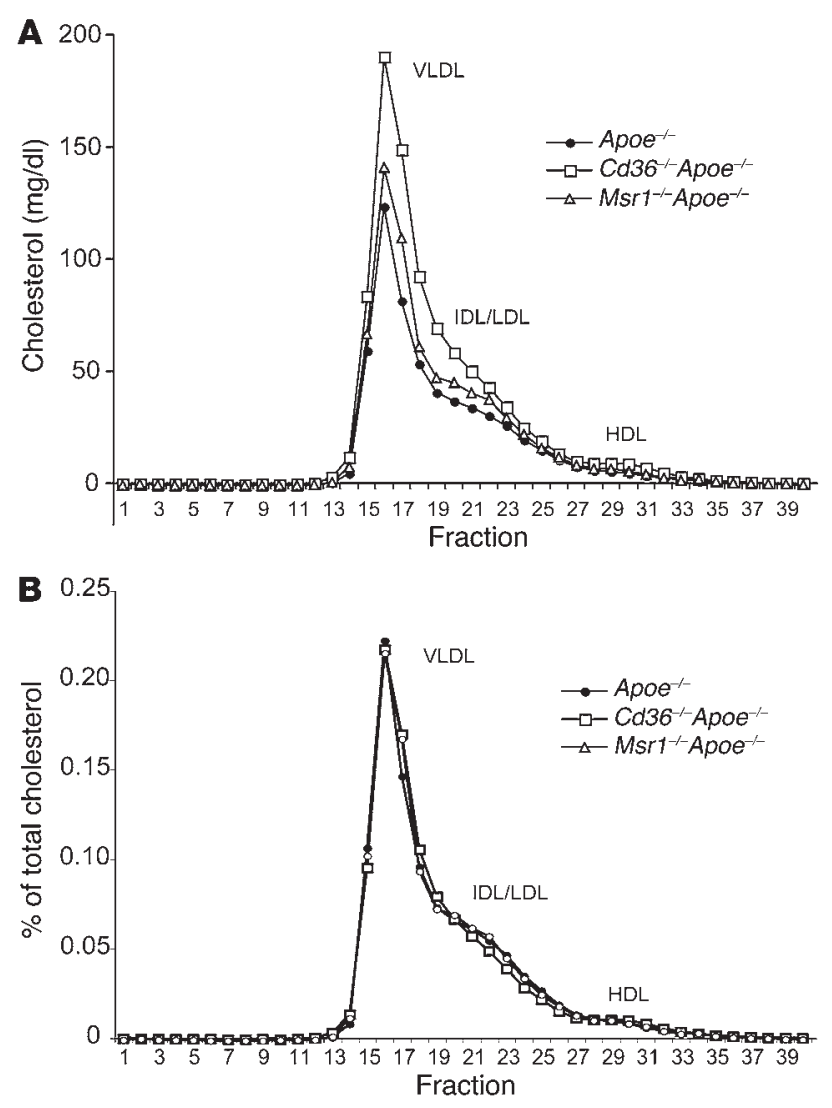

Cd36 does not alleviate aortic sinus atherosclerosis, and in fact, may increase lesion size in this site. It is interesting to note that male $\mathrm{Msr1}^{\mathrm{I}^{-1}} \mathrm{Apoe}^{-/-}$and $\mathrm{Cd} 3 \mathrm{6}^{-/-} \mathrm{Apoe^{-/- }}$ mice showed the largest increase in aortic sinus lesion area despite the reduction in peritoneal macrophage cholesterol and cholesterol ester content.

To assess atherosclerotic lesion formation in areas outside of the aortic sinus, we measured intimal lipid accumulation from the arch to the ileal bifurcation of aortae stained with Sudan IV. No significant differences in total lesion area of the en face aorta were observed among male Apoe ${ }^{-/-}, \mathrm{Msr1}^{-/-} \mathrm{Apoe}^{-/-}$, and $\mathrm{Cd} 36^{-/-} \mathrm{Apoe^{-/- }}$ mice (Figure $3 \mathrm{~A})$. Sudan IV staining assessment of lesions at different sites in the aortic tree revealed no significant differences in the aortic arch or the ileal bifurcation among the 3 groups; $\mathrm{Msr1}^{-/-}$ Apoe ${ }^{-/-}$males showed a substantial increase in thoracic lesions and a modest decrease in abdominal lesions, but substantial variability among the animals assessed in this group makes it difficult to conclude that the regional variations are meaningful (data not shown). Similarly, no difference in total en face lesion area was observed between female Apoe $e^{-/-}$and $\mathrm{Msr1}^{-{ }^{-}} \mathrm{Apoe^{-/- }}$ mice; however, a $30 \%$ decrease that resulted from significantly less lipid accumulation in the thoracic-abdominal region of the aorta was detected in female Cd36-/- Apoe $^{-/-}$mice $\left(2.92 \pm 1.19\right.$ Apoe $^{-/-}$vs. $1.43 \pm 0.70$ Cd36 $6^{-/-}$Apoe $^{-/-}$) (Figure 3, A and B). No significant differences in en face lipid accumulation were detected in the aortic arch or ileal bifurcation regions in these mice. Thus, there was a discordance in the development of atherosclerotic lesions in the aortic sinus and distal aorta in the absence of Cd36. The elimination of this scavenger receptor may alter cellular lipid accumulation in the arterial tree, leading to decreased lesion area as detected by en face mea-

\section{Figure 1}

Distribution of cholesterol in plasma lipoproteins from $\mathrm{Apoe}^{-/-}, \mathrm{Cd} 36^{-/-}$ Apoe $^{-/}$, and $\mathrm{Msr1}^{-1-} \mathrm{Apoe}^{-/-}$mice. Pooled plasma samples $(\mathrm{n}=3$

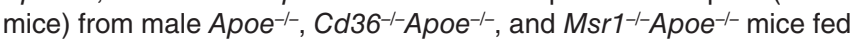
a Western diet for 8 weeks were separated by FPLC, and fractions were assayed for cholesterol. (A) FPLC profile demonstrating the concentration of cholesterol in each fraction. (B) Normalized FPLC profile demonstrating a similar distribution of cholesterol to lipoproteins in all 3 genotypes when the cholesterol in each fraction is expressed as a percentage of the total cholesterol recovered from the column. Closed circles, $A p o e^{-/-}$mice; open squares, $C d 36^{-1-} A p o e^{-/-}$mice; open triangles, $\mathrm{Msr1}^{-1-} \mathrm{Apoe}^{-/-}$mice.

surement, which is not reflected in the intimal area measurements that are performed in the aortic sinus.

Histological analyses of aortic sinus lesions revealed no significant differences in cellular lipid or smooth muscle cell content in atherosclerotic plaques of $\mathrm{Apoe^{-/- }}, \mathrm{Msr}^{-/-} \mathrm{Apoe}^{-/-}$, and $\mathrm{Cd}_{36^{-/-}} \mathrm{Apoe^{-/- }}$ mice. When normalized to percentage of total lesion area, the amount of oil red $O$ and $\alpha$-SMA staining was similar in lesions from mice of all 3 genotypes in both sexes (Figure 4A). Interestingly, despite $20-40 \%$ increases in aortic sinus lesion area in Cd36 $6^{-1-} \mathrm{Apoe}^{-/-}$mice, there was a decrease in macrophage content as measured by MOMA-2 staining (Figure 4B). This difference was statistically significant only in female $\mathrm{Cd} 36^{-1-}$ Apoe $e^{-/-}$mice, in which aortic sinus lesions contained $40 \%$ fewer macrophages per total lesion area. During pathological examination of these lesions, we observed a greater number of advanced lesions in $\mathrm{Cd} 36^{-/-} \mathrm{Apoe^{-/- }}$ female mice than in Apoe $e^{-/-}$mice of the same sex (Fig 5b). These lesions contained large acellular regions, characteristic of a necrotic lipid core, and few macrophage foam cells (Figures 4B and 5A). Atherosclerotic lesions in $A p o e^{-/-}$female mice contained smaller cholesterol clefts and showed less medial damage and greater macrophage accumulation. Levels of collagen content were similar in lesions from all 3 genotypes (Figure 5B). This finding suggests that loss of lipid uptake via CD36 may increase extracellular lipid accumulation and/or contribute to apoptosis of macrophage foam cells, leading to the formation of a necrotic core. Alternatively, the reduction in macrophages in atherosclerotic lesions of $\mathrm{Cd} 36^{-/-}$ Apoe ${ }^{-/-}$mice may be due to reduced macrophage recruitment or retention, as we have previously shown that a CD36-associated signal transduction pathway activated by amyloid ligands modulates expression of macrophage chemokines, including macrophage

\section{Table 2}

Reduced cholesterol ester accumulation in macrophages from

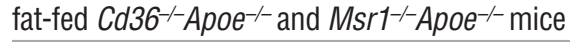

\begin{tabular}{|c|c|c|c|}
\hline \multirow[b]{2}{*}{ Genotype } & \multirow[b]{2}{*}{$n$} & \multicolumn{2}{|c|}{ Cholesterol (ug/mg protein) } \\
\hline & & Free & Esterified \\
\hline \multicolumn{4}{|l|}{ Male } \\
\hline Apoe $e^{-/}$ & 7 & $1,485 \pm 691$ & $1184 \pm 304$ \\
\hline$C d 36^{-/-}$Apoe $e^{-/-}$ & 5 & $630 \pm 249 A$ & $356 \pm 156^{A}$ \\
\hline Msr1-/-Apoe ${ }^{-/-}$ & 9 & $865 \pm 163^{A}$ & $244 \pm 123^{A}$ \\
\hline \multicolumn{4}{|l|}{ Female } \\
\hline Apoe ${ }^{-/-}$ & 7 & $740 \pm 132$ & $124 \pm 121$ \\
\hline$C d 36^{-1-}$ Apoe $e^{-/-}$ & 7 & $718 \pm 148$ & $188 \pm 177$ \\
\hline Msr1-/-Apoe ${ }^{-/-}$ & 3 & $491 \pm 228$ & $107 \pm 37$ \\
\hline
\end{tabular}

AP $<0.05$, as compared with $A p o e^{-1-} ; 2$-tailed Student's $t$ test. 
A

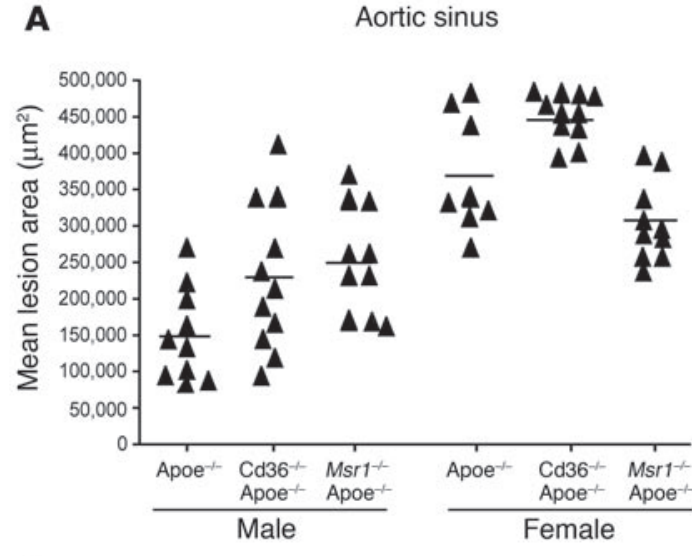

c

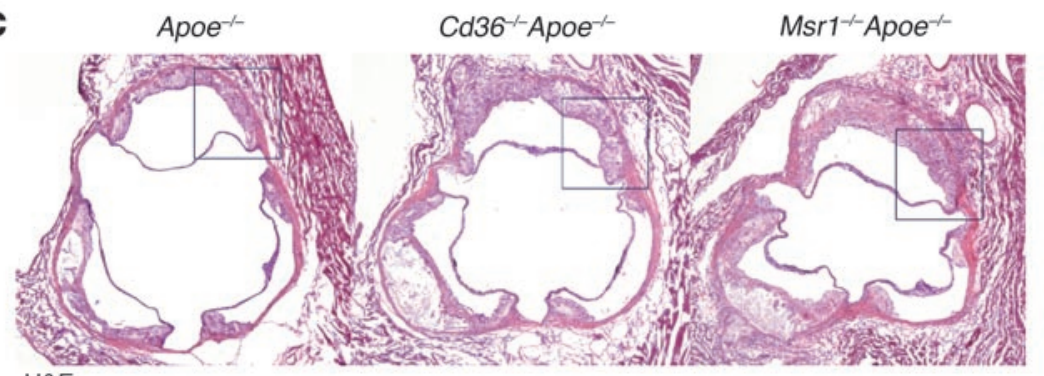

$H \& E$
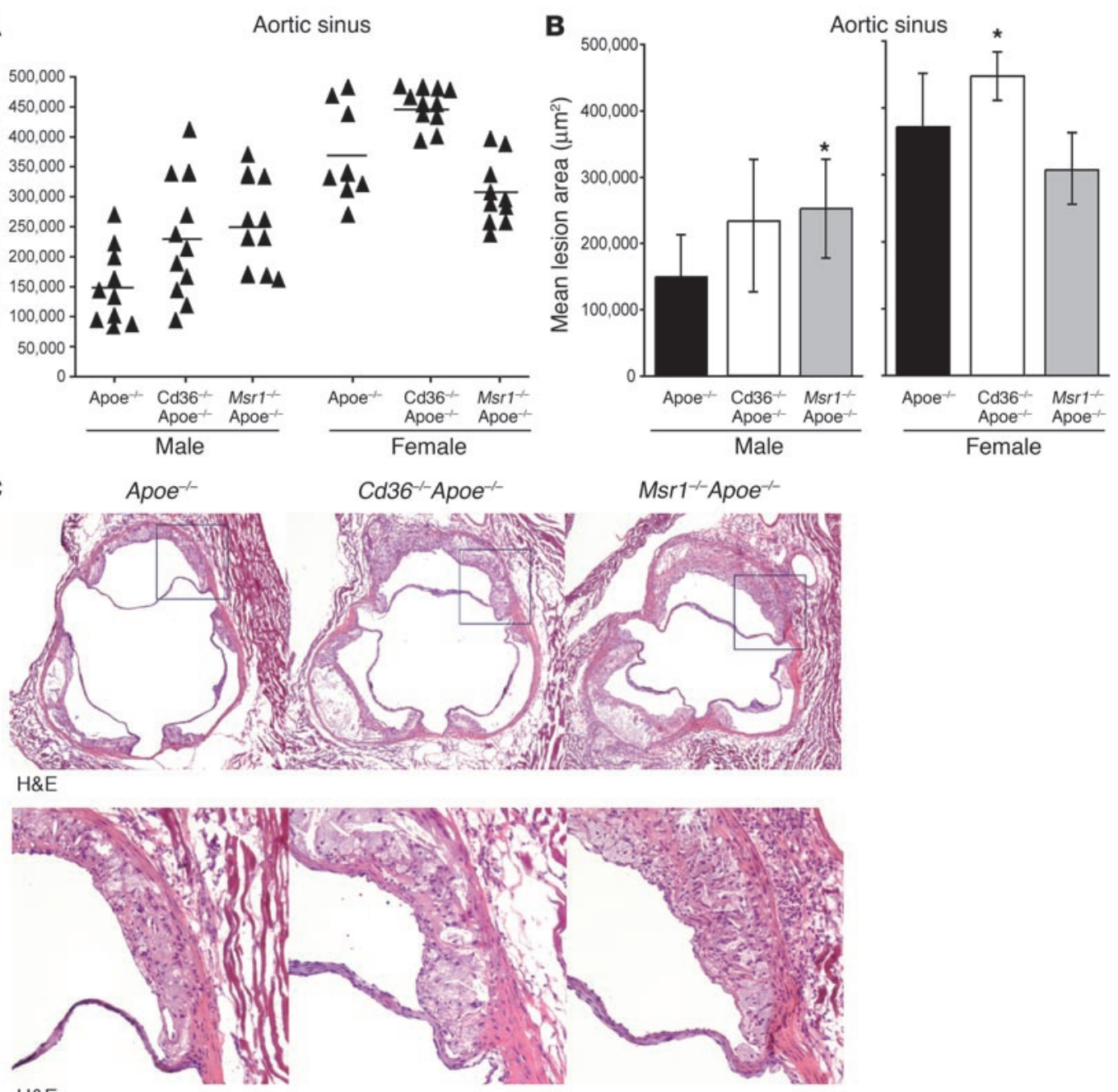

$H \& E$

\section{Figure 2}

Disruption of Cd36 or Msr1 increases aortic sinus atherosclerosis in Apoe-/- mice. Aortic sinus atherosclerotic lesion area was quantified from serial sections (12 sections per mouse) cut through the aorta at the origins of the aortic valve leaflets that were stained with oil red $\mathrm{O}$ and hematoxylin. (A) Dot plot showing aortic sinus lesion area of individual mice, with mean lesion area shown in (B). ${ }^{\star} P \leq 0.05$; significantly different from Apoe ${ }^{-/-}$control mice. (C) Representative photographs of the aortic sinus from male Apoe ${ }^{-/}, \mathrm{Cd}_{36^{-/}} \mathrm{Apoe}^{-/-}$, and $\mathrm{Msr1}^{-/-} \mathrm{Apoe^{-/ }}$ mice stained with H\&E. Magnification, $\times 60$ (top row); $\times 200$ (bottom row).

chemoattractant protein-1 (MCP-1), known to play a role in atherogenesis (19-21). We are currently conducting longer studies in these mice to address how the loss of scavenger receptors affects lesion progression and stability at later stages of atherosclerosis.

To explore further the relationship between macrophage scavenger receptor activity and in vivo foam cell formation, aortic sinus lesions of all 3 mouse genotypes were assessed by electron microscopy. Aortic sinus lesions of female Apoe-/-, $\mathrm{Msr1}^{-/-} \mathrm{Apoe}^{-/-}$, and $\mathrm{Cd}_{36^{-/}} \mathrm{Apoe}^{-/-}$mice all showed dramatic accumulations of lipid within cells in the intimal space that are characteristic of macrophages (Figure 6A). Lower-power images confirmed an abundance of lipid-laden foam cells in the intimas of $\mathrm{Msr1}^{-/-}$ Apoe ${ }^{-/-}$and $\mathrm{Cd}^{-16^{-/}} \mathrm{Apoe}^{-/-}$aortae that was indistinguishable from that in control Apoe $e^{-/-}$mice (not shown). These images establish that abundant foam cell formation occurs in the arterial intima in the absence of SR-A or CD36, suggesting that other scavenger receptors can fully compensate for these receptors or that lipid uptake occurs by alternative mechanisms. Although the molecular structure of the lipoproteins taken up by lesional macrophages remains uncertain, we tested whether aggregated, nonoxidized LDL could be internalized by cells lacking either scavenger receptor. Figure $6 \mathrm{~B}$ shows that native monomeric LDL causes very little cholesterol ester accumulation in macrophages and that the small amount of lipid that is taken up under these conditions is unaffected by the presence or absence of scavenger receptors. In contrast, aggregated LDL causes a massive accumulation of cholesterol ester, but this process is also not impaired by the absence of scavenger receptors (Figure 6B). Taken together, these findings demonstrate that in the setting of hyperlipidemia, abundant macrophage foam cell formation occurs in vivo in both $\mathrm{Msrl}^{-/-} \mathrm{Apoe}^{-/-}$and $\mathrm{Cd}_{3} \mathrm{6}^{-/-} \mathrm{Apoe}^{-/-}$mice and that it is possible to generate macrophage foam cells in vitro using a modified form of LDL that does not depend on scavenger receptors for its uptake. 

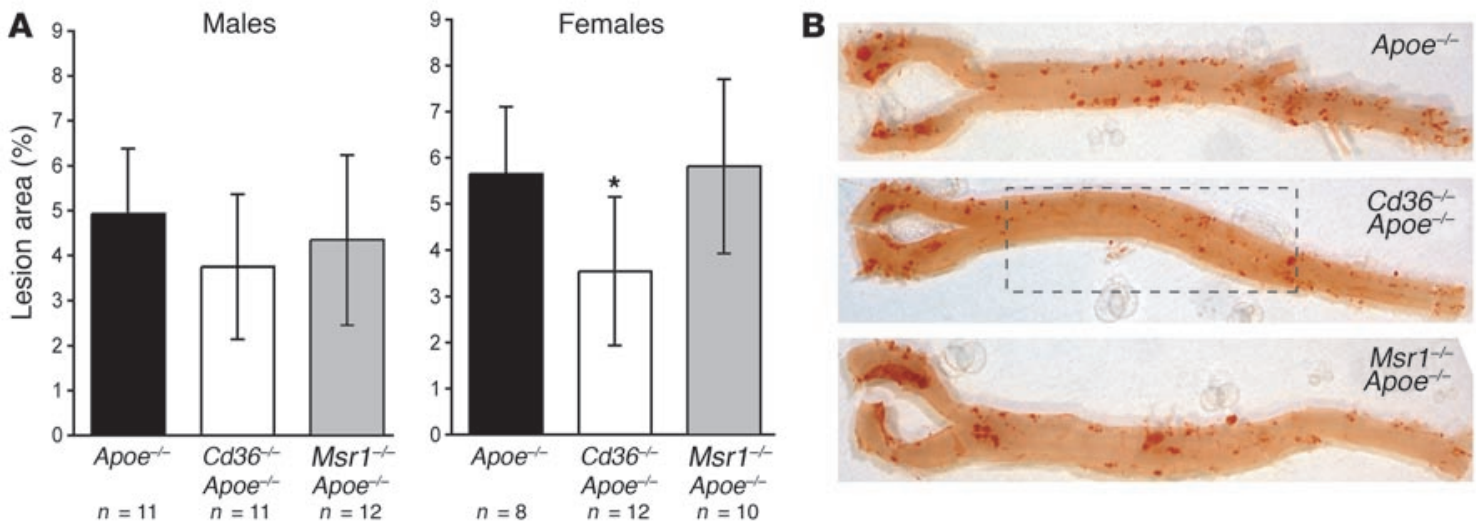

Figure 3

Morphometric analysis of lesion area in the aortic tree. Aortae were stained en face with Sudan IV, and lesion area was measured as a percentage of total aortic area. (A) Lesion area in male and female mice. ${ }^{*} P \leq 0.05$; significantly different from Apoe ${ }^{-/}$control mice. (B) Representative photographs of the en face aortae from female $\mathrm{Apoe}^{--}, \mathrm{Cd}_{3} 6^{--} \mathrm{Apoe}^{--}$, and $\mathrm{Msr1}^{-/-} \mathrm{Apoe}^{-/}$mice. The boxed region indicates the area of reduced lesions observed in the $\mathrm{Cd} 36^{-/-}$Apoe $\mathrm{e}^{-/-}$female mice.

\section{Discussion}

Current concepts of atherogenesis attribute foam cell formation to scavenger receptor-mediated macrophage lipid uptake pathways. As foam cell formation has long been deemed critical to lesion development, the scavenger receptors involved in lipid uptake have been causally implicated in the pathogenesis of atherosclerosis. Several studies, though not all, have shown that targeted deletion of either Msr1 or Cd36 in hyperlipidemic mouse models leads to a reduction in atherosclerosis (5-9). Furthermore, our own in vitro studies have demonstrated that macrophages lacking both SR-A and CD36 show an 80-90\% reduction in the internalization and degradation of lipoproteins modified by either acetylation or oxidation (16). If the oxidized modified lipoproteins used in in vitro experiments appropriately represent the major form of lipoprotein taken up by macrophages in the arterial intima, these data suggest that preventing lipid uptake via these 2 pathways might abrogate macrophage foam cell formation in vivo and, subsequently, atherosclerotic lesion development.

Although the scavenger receptor-foam cell paradigm has proven very compelling, a number of studies have utilized nonoxidized forms of LDL and generated macrophage foam cells via pathways that remain undefined or do not have characteristics consistent with scavenger receptor involvement. These alternative pathways include both receptor- and nonreceptor-mediated mechanisms. Kruth and colleagues have recently demonstrated that macrophages can accumulate substantial quantities of lipids via macropinocytosis of LDL particles, thus identifying a non-receptor-mediated pathway by which foam cells could form in vivo $(13,22,23)$. Other investigators have shown that enzyme modifications generated by exposure of LDL to secretory phospholipase A2 can convert native LDL into a structure that readily engenders foam cell formation (24). Both Fc and LDL receptor-related protein (LRP) receptors have been implicated in the uptake of LDL that has been bound by antibodies or modified by other processes (25-28). Thus, despite substantial evidence that oxidized forms of LDL are produced in the arteries of both mice and humans, there are no definitive data that establish that the lipid that generates foam cells in either species derives from oxidized lipoproteins, as opposed to native, aggregated, or nonoxidatively modified forms of LDL. As the con- centrations of native or aggregated LDL determined in human intimal samples typically exceed $100 \mathrm{mg} / \mathrm{dl}$, these forms of LDL may provide substantially greater amounts of lipid than can be taken up by the scavenger receptor pathways, which saturate at lipoprotein concentrations of $25-50 \mu \mathrm{g} / \mathrm{ml}(29,30)$. Moreover, if mice lacking scavenger receptor expression take up fewer modified lipoproteins, this raises the important issue of the fate of these lipoproteins in the artery wall. Given the multiple cellular toxicities associated with exposure to oxidized lipoproteins (31), it is not clear why a failure to internalize such particles would result in reduced damage to the artery wall. Thus, if scavenger receptor inactivation does result in amelioration of atherosclerosis, this suggests that alternative, less atherogenic uptake mechanisms compensate for the absence of scavenger receptors or that oxidized lipoproteins might not be present in sufficient amounts in the artery wall to cause the toxicities reported in in vitro studies.

To explore this issue further, we set out to examine the importance of receptor-mediated lipid uptake by evaluating atherosclerosis in Apoe $\mathrm{Al}^{-/}$mice with targeted deletions of both Msr1 and Cd36. In the course of undertaking these experiments, we found that we could not replicate the previously reported atherosclerosis benefit in mice with individual deletions of $M s r 1$ and Cd36. After 7 generations of backcrossing into the $\mathrm{C} 57 \mathrm{BL} / 6$ genomic background, Cd36- $6^{-/-} \mathrm{Apoe}^{-/-}$and $\mathrm{Msr} \mathrm{1}^{-/-} \mathrm{Apoe^{-/- }}$ mice, which were our control groups for triple-knockout $\left(\mathrm{Cd} 36^{-/-} \mathrm{Msr1}^{-/-} \mathrm{Apoe^{-/ }}\right)$ mice, exhibited increased serum cholesterol levels and larger aortic sinus atherosclerotic lesions, as compared with $A p o e^{-/-}$mice. These findings suggest that scavenger receptor-mediated lipid uptake protected against atherosclerosis lesion formation rather than promoted it.

The results of our study, indicating that loss of either Msr1- or Cd36-mediated lipid uptake does not inhibit atherosclerotic lesion progression, are not easily reconciled with several earlier studies $(6-9,32)$. In the case of CD36, 2 studies have been reported that directly addressed the role of atherosclerosis in mice lacking both apoE and CD36. The first study used mice with a global deletion of the receptor while the second utilized bone marrow transplantation of myeloid cells lacking the protein $(8,32)$. In the global deletion experiment, $\mathrm{Cd} 36^{-/-} \mathrm{Apoe}^{-/-}$mice backcrossed 4 generations into the C57BL/6 background ( 93.8\% C57BL/6) and fed for 12 

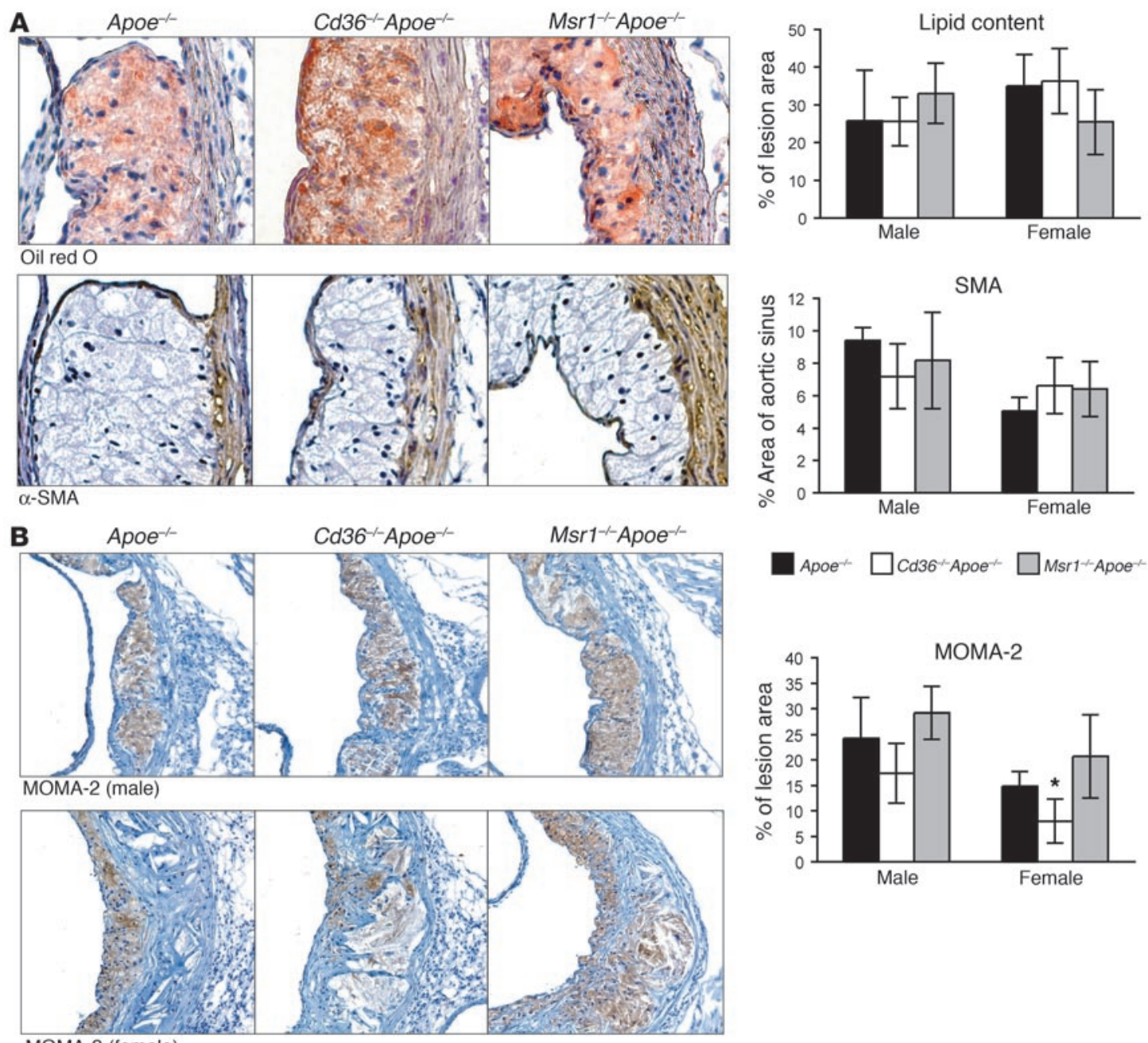

\section{Figure 4}

Immunohistochemical characterization of aortic sinus atherosclerosis. Aortic sinus lesions from $\mathrm{Apoe}^{-/-}, \mathrm{Cd}_{36} \mathrm{~S}^{-/} \mathrm{Apoe^{-/ }}$, and $\mathrm{Msr}^{-/-} \mathrm{Apoe^{-/ }}$ mice were stained for neutral lipid (oil red O), SMC ( $\alpha$-actin) and macrophage content (MOMA-2). Staining was quantified using IP Lab Spectrum image analysis software and is presented graphically. (A) Representative photographs of aortic sinus lesions from male Apoe ${ }^{-/}$, $\mathrm{Cd} 36^{-/-} \mathrm{Apoe}^{-/-}$, and $\mathrm{Msr}^{-/-} \mathrm{Apoe}^{-/-}$mice stained with oil red $\mathrm{O}$ and anti-smooth muscle actin ( $\alpha$-SMA). Magnification, $\times 400$. (B) Representa-

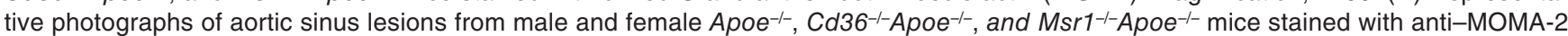
antibody to detect macrophages. Fewer macrophages were detected in female $\mathrm{Cd}_{36^{-/}} \mathrm{Apoe}^{-/-}$mouse lesions than in $A p o e^{-/-}$mouse lesions. ${ }^{*} P \leq 0.05 ;$ ANOVA. Magnification, $\times 100$.

weeks with the same diet used in our study had profound (70-82\%) reductions in atherosclerosis, as detected by oil red $\mathrm{O}$ uptake in the aortic tree, when compared with nonlittermate Apoe $e^{-/-}$mice backcrossed 10 generations to $\mathrm{C} 57 \mathrm{BL} / 6$. Interestingly, the aortic sinus atherosclerosis measurements, which quantitate actual lesion area and not just the area of aorta stained for lipid, were less profoundly influenced. Cd36 $6^{-/-}$Apoe $e^{-/-}$male mice on the Western diet had a $45 \%$ reduction in aortic sinus lesion size whereas the atheromas in the $\mathrm{Cd} 36^{-/-}$Apoe $e^{-/-}$females were slightly larger (not statistically significant) than the atheromas in their wild-type counterparts. However, these 2 measurements were performed on a relatively small group of mice $\left(n=5-6 ; \mathrm{Cd}^{2} 6^{-/-}\right)$. A larger group of mice on a chow diet were analyzed $\left(n=9-13\right.$; $\left.\mathrm{Cd} 36^{-/-}\right)$; in these, lesion sizes were found to be smaller in both male and female Cd36 $6^{-1-} \mathrm{Apoe}^{-/-}$mice, but the differences were only statistically significant in males. A recently published bone marrow study (32) used mice backcrossed an additional time ( $96.9 \%$ C57BL/6) and reported an $88.1 \%$ decrease in total en face aortic lesion area in the mice receiving marrow lacking CD36, using only the lipid staining technique to quantitate atherosclerosis.

Three factors emerge as possible explanations for the different outcomes we measured. The first is the difference in strain background, as our mice were backcrossed into C57BL/ 6 mice 2 to 3 generations more than those utilized in the reports just cited. That strain background can influence outcome in mouse atherogenesis studies is evident from several lines of investigation $(33,34)$. In one especially relevant study of this issue, $\mathrm{Ldlr}^{-/-}$mice with a targeted deletion in Rag1 were crossed 4 (93\% C57BL/6) or 10 (99\% $\mathrm{C} 57 \mathrm{BL} / 6)$ generations into $\mathrm{C} 57 \mathrm{BL} / 6$ with the finding that the mice with the $6 \%$ lower C57BL/ 6 genome had $35-40 \%$ less aortic sinus atherosclerosis (33). Given the growing number of mapped atherosclerosis susceptibility loci in the mouse, it is perhaps not 
A $\quad$ Apoe $^{--}$

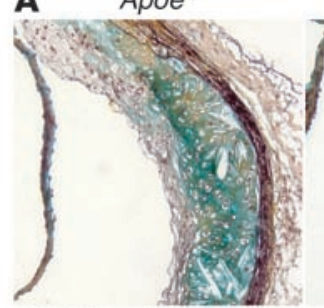

Movat's stain

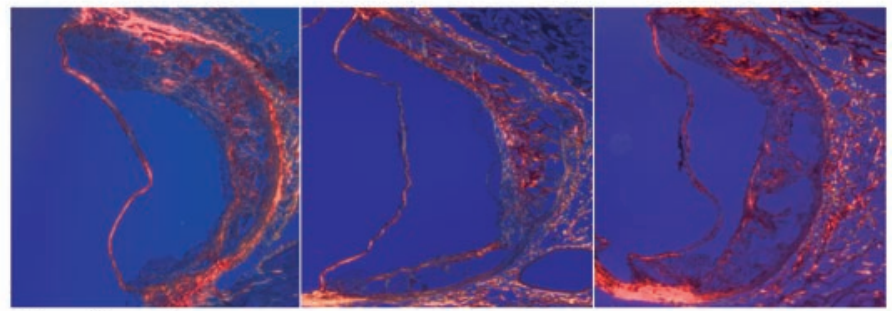

Cd36-Apoe $6^{-1-}$

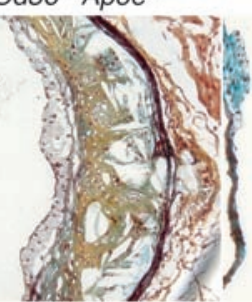

$\mathrm{Msr1}^{-1-} \mathrm{Apoe}^{-1-}$

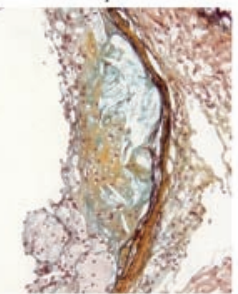

Picrosirius red

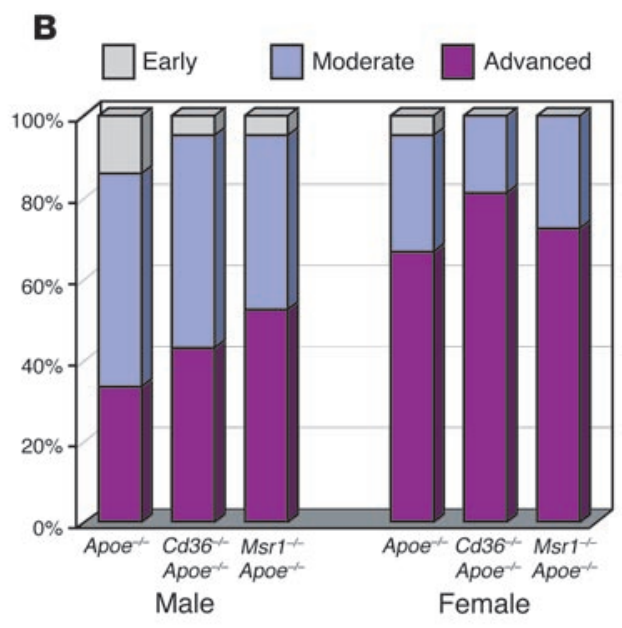

\section{Figure 5}

Histological staining of aortic sinus lesions from female Apoe ${ }^{-/}, \mathrm{Cd} 36^{-/-} \mathrm{Apoe^{-/ }}$, and $\mathrm{Msr1} \mathrm{1}^{-/-}$Apoe $\mathrm{e}^{-/}$mice with (A) Movat's pentachrome stain (top panel) to identify cells (red), collagen (yellow), and glycosaminoglycans (blue), and picrosirius red stain (bottom panel) for type 3 collagen. Magnification, $\times 200$ (top panel); ×100 (bottom panel). (B) Classification of aortic sinus lesions according to severity: (a) early lesions contained only foam cells; (b) moderate lesions contained additional smooth muscle cells in the intima and cap; and (c) advanced lesions contained large extracellular cholesterol clefts or lipid cores and exhibited disruption of the coherence of the media and thick layers of fibrous connective tissue.

surprising that differences in genomic strain composition outside of a specifically targeted locus of interest might confound interpretations of lesion development. While the use of littermate controls can reduce the possibility of this confounding error, it does not eliminate it. Moreover, the use of double- and triple-knockout mice limits the ability to produce and use $A p o e^{-/-}$littermates as the control population. With the sequencing of the mouse genome, it is now possible to develop many more polymorphic markers across the genome. It may be prudent in future studies of murine atherosclerosis to characterize the homogeneity of the background strain using these markers before undertaking the lengthy and laborious task of quantitating atherosclerosis lesion area.

The second factor that emerges in the $C d 36^{-/-}$analyses revolves around the method of quantitating atherosclerosis lesion area. In our study, we also found decreases in lesion area in mice lacking CD36 when this parameter was measured by en face staining of lipid accumulation in the aortae. While the differences in en face lesion area that we measured in $\mathrm{Cd} 36^{-1-} \mathrm{Apoe}^{-/-}$compared with Apoe ${ }^{-/-}$mice were much less profound than those reported in the previous studies $(30 \%$ versus $70-90 \%)(8,32)$ and were only statistically significant in female mice, these findings were discordant with the measurements of intimal lesion area at the aortic sinus. As the elimination of either SR-A or CD36 can substantially alter lipid uptake in macrophages and thus would be predicted to alter

\section{Figure 6}

Abundant foam cell formation occurs in the absence of SR-A and CD36. (A) Electron photomicrographs demonstrating cellular lipid accumulation in the intima of aortic sinus lesions from $\mathrm{Apoe}^{-/-}, \mathrm{Cd} 36^{-/-}$ Apoe $^{-1}$, and Msr1--Apoe ${ }^{-/-}$mice. Magnification, $\times 3900$. (B) Aggregated, but not native, LDL (AgLDL) induces abundant cholesterol ester accumulation in $\mathrm{Apoe}^{-/-}$macrophages that is independent of $\mathrm{Cd} 36$ or Msr1. Cellular cholesterol ester was measured by GC-MS in triplicate samples and is expressed as the mean \pm SD.

the pattern and intensity of oil red $\mathrm{O}$ staining in the arterial tree, we think it likely that the use of lipid staining as an indicator of lesion size could be problematic under these circumstances. As noted above, the previous study in CD36 null mice in which aortic sinus lesion area was directly measured showed less atherosclerosis only in males (8), and this difference was much smaller than that seen when quantitation of oil red $\mathrm{O}$ staining was employed.

Finally, our study was conducted for 8 weeks in order to assess early lesion initiation and progression, while the first report of the impact of CD36 on atherosclerosis in mice was a 12-week investigation. Although the time frame of analyses can certainly affect atherosclerosis outcome, van der Westhuyzen and colleagues have reported a 16-week study of atherosclerosis in $\mathrm{Ldlr}^{-/-}$mice trans-

A
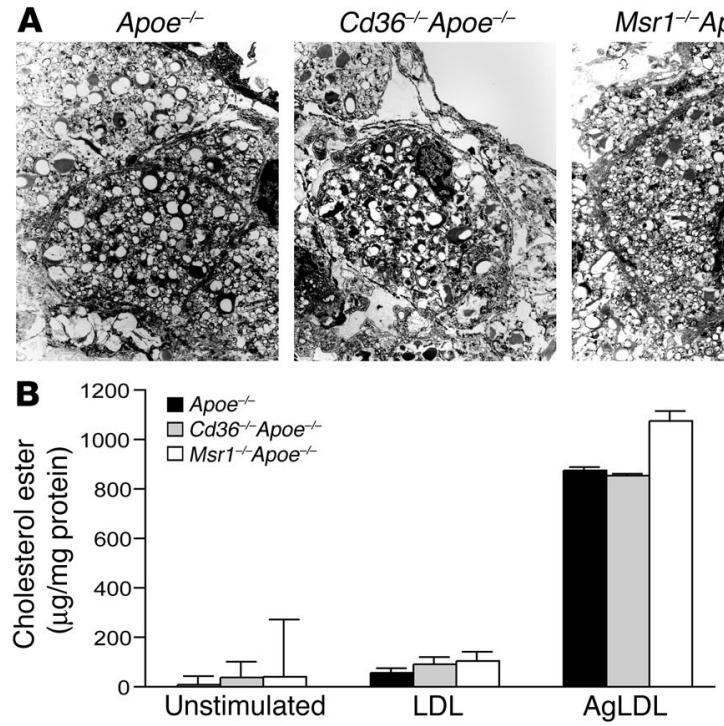
planted with marrow cells lacking CD36; this study also failed to detect any impact of this receptor on atherosclerosis (personal communication, Deneys van der Westhuyzen, Chandler Medical Center, University of Kentucky, Lexington, Kentucky, USA). These results differ from those seen in the bone marrow transplantation experiment in the Apoe $e^{-/}$mice described above (32). A recent study from the van der Westhuyzen group has shown that LDL derived from Apoe $e^{-/-}$mice is a better ligand for CD36 and SR-A than that from $\mathrm{Ldlr}^{-/}$mice, which can promote macrophage foam cell formation without prior modification. The atherogenicity of Apoe ${ }^{-/-}$LDL was shown to be due to an increased state of oxidation and cholesterol content, which may lead to differences in these 2 mouse models of atherosclerosis (35). While differences between Apoe ${ }^{-/-}$and $\mathrm{Ldlr}^{-/-}$mice could account for the divergent results, the findings suggest that the role of CD36 in hyperlipidemic atherosclerosis may not be as critical as previously thought.

While several of the same considerations apply to the study of $\mathrm{Msr}^{-/-}$mice, a larger and more complex set of studies have been performed in both Apoe-/- and $\mathrm{Ldlr}^{-/-}$models of murine atherosclerosis $(5-7,9,17,36)$. These have provided conflicting results, making the contribution of SR-A to atherogenesis more controversial. In perhaps the most widely quoted study of SR-A involvement in atherosclerosis, in $\mathrm{Ldlr}^{-/}$mice fed a butterfat diet, Babaev et al. reported a marked reduction in atherosclerosis in mice lacking SR-A (7). These authors also cited genomic background differences in their attempt to resolve the discrepant SR-A results reported. In their own studies, they addressed this issue by using mice that had been backcrossed 6 generations into the C57BL/ 6 background ( $98.4 \%)$. Some of the studies of SR-A involvement in murine atherosclerosis that have yielded results more consistent with our own findings $(17,36-38)$ appear to have used approaches in which the issues of background strain differences have been well addressed, but in others, the genomic background may well have played a significant role in the reported outcome. Interestingly, comparisons of atherosclerosis-susceptible and -resistant mouse and rabbit models have shown that SR-A expression is increased in animals with low atherosclerotic responses, further suggesting that this pathway is protective $(39,40)$.

A particularly intriguing finding of our study is that male $\mathrm{Cd} 36^{-/-}$ and $\mathrm{Msr}^{-1-}$ mice, which exhibited the most profound reduction in in vivo foam cell formation as measured by the cholesterol and cholesterol ester content of peritoneal macrophages, were the animals with the greatest increase in atherosclerosis lesion size in the aortic sinus. The reason for the difference between sexes in lipid accumulation in macrophages is unclear, but the results in the males suggest that lipid uptake by scavenger receptors may in fact protect against atherosclerosis lesion development. Further studies of mice lacking both Msr1 and Cd36 should help clarify this issue and permit some further refinement in the paradigm of scavenger receptor involvement in atherogenesis.

\section{Methods}

Mice. $\mathrm{Msr}^{-/-}$mice were originally provided by $\mathrm{T}$. Kodama (University of Tokyo, Tokyo, Japan) (9) and were crossed with C57BL/6J Apoe $e^{-/-}$mice from Jackson Laboratory to generate $\mathrm{Msr}^{+/-} \mathrm{Apoe}^{+/-}$mice. These mice were backcrossed an additional 6 generations into the $\mathrm{C} 57 \mathrm{BL} / 6 \mathrm{~J}$ strain and intercrossed to generate $\mathrm{Msr}^{-/-} \mathrm{Apoe^{-/- }}$ mice. $\mathrm{Cd} 36^{-/-} \mathrm{Apoe^{-/- }}$ mice backcrossed 4 generations into the $\mathrm{C} 57 \mathrm{BL} / 6 \mathrm{~J}$ strain were originally provided by R. Silverstein and M. Febrraio (Weill Medical College of Cornell University, Ithaca, New York, USA) (8) and were backcrossed into the same strain an additional 3 generations. $\mathrm{Cd} 36^{+/-} \mathrm{Apoe^{+/- }}$ mice were intercrossed to produce $\mathrm{Cd} 36^{-/} \mathrm{Apoe}^{-/-}$mice at the expected ratio of 1:16. After 7 generations of backcrossing, these mice are predicted to have approximately $99 \%$ of their genome derived from the $\mathrm{C} 57 \mathrm{BL} / 6 \mathrm{~J}$ strain. The genetic backgrounds of both the $\mathrm{Msr}^{-/-} \mathrm{Apoe} \mathrm{e}^{-/-}$and the $\mathrm{Cd} 36^{-/} \mathrm{Apoe}^{-/-}$mice were assessed by genome scanning, using 100 polymorphic markers that distinguish the $\mathrm{C} 57 \mathrm{BL}$ genome from the mouse strain in which the original targeted recombination event took place (i.e., 129Sv). A total of 97 or 98 of 100 markers mapped to C57BL/6J in each of the 2 strains, with the mice retaining 129 markers at the sites closest to the genes targeted for inactivation and selected for retention in the breeding program (e.g., the marker closest to the Apoe locus on chromosome 7). C57BL/6J Apoe $e^{-/-}$mice from the Jackson Laboratory were used as controls. Beginning at 6-8 weeks of age, mice were fed a Western-type diet (Teklad Adjusted Calories 88137: $21 \%$ [wt $/ \mathrm{wt}]$ fat; $0.15 \%[\mathrm{wt} / \mathrm{wt}$ ] cholesterol; $19.5 \%$ [wt/wt] casein, no sodium cholate). After 8 weeks on the diet, mice were euthanized and tissue, blood, and aorta samples were collected for analysis and genotyping as we previously described (41). Serum total cholesterol and triglyceride concentrations were determined by enzymatic assay (Sigma-Aldrich). Mice were maintained in a pathogen-free environment. Experimental procedures were approved by the Massachusetts General Hospital's Subcommittee on Research Animal Care and were conducted in accordance with the USDA Animal Welfare Act and the Public Health Service Policy for the Humane Care and Use of Laboratory Animals.

In vivo and in vitro foam cell formation assays. For assessment of in vivo foam cell formation, peritoneal macrophages were isolated from hyperlipidemic mice after 8 weeks on the Western diet as previously described (16). Briefly, mice were injected i.p. with $1 \mathrm{ml}$ of $3 \%$ thioglycollate, and peritoneal exudates were collected by lavage after 4 days. Cells were cultured overnight in DMEM containing 5\% FBS, and adherent macrophages were stained with oil red $\mathrm{O}$ or extracted with hexane:isopropanol as previously described (42). Total cholesterol and cholesterol ester were determined from lipid extracts by GC-MS as we previously described (42). Similar techniques were used to measure in vitro foam cell formation with aggregated LDL, except that peritoneal macrophages were elicited from mice that were chow fed. LDL was aggregated by vortexing ( 1 minute) and collected by centrifugation at $12,000 \mathrm{~g}$ for 15 minutes as described (43). The supernatant was subjected to vortexing and centrifugation an additional 3 times, and precipitates were recombined. Macrophages were incubated with $100 \mu \mathrm{g} / \mathrm{ml}$ of aggregated LDL or native LDL for 48 hours, and lipids were extracted with hexane:isopropanol for GC-MS analysis as described above.

Measurement of atherosclerotic lesions. Atherosclerotic lesion area was quantified on cross-sections of the aorta beginning at the level of the aortic sinus and en face in the aortic arch and descending aorta by Sudan IV staining as we described $(41,44,45)$. Mice were anesthetized by i.p. injection with Avertin $(0.4 \mathrm{mg} / \mathrm{g}$ body wt), and the arterial system was perfusion-fixed with $10 \%$ formalin. The heart and upper section of aorta was removed, cleaned of peripheral fat under a dissecting microscope, and sectioned directly under and parallel to the aortic leaflets. The upper section was embedded in OCT medium and snap-frozen. Every third section (5- $\mu \mathrm{m}$ thick) throughout the aortic sinus $(400 \mu \mathrm{m})$ was taken for analysis. Sections were stained with $\mathrm{H} \& \mathrm{E}$ and oil red $\mathrm{O}$ and quantified using digitally captured sections and the quantitative image analysis software IP Lab Spectrum version 3.9 (Scanalytics). Lesion area is reported as the mean of 12 sections per mouse. The delineation of atherosclerotic lesion area was determined by a single observer, blinded to the genotype of the mice. For quantification of lesions in the descending aorta, the aorta was dissected so that it was free of all branching vessels, stained, en face, with Sudan IV for 15 minutes, destained with $70 \%$ ethanol for 30 seconds, and stored in water. Stained aortae were incised ventrally from the aortic root to the bifurcation of the iliac arteries, laid flat 
on glass slides, and covered by a coverslip. Images of stained aortae were digitally captured and lesion area selected with IP Lab Spectrum software using predefined Sudan IV staining parameters to distinguish atherosclerotic regions within the aorta. Lesion area was calculated as a percentage of the total area of the whole aorta or defined regions of the aorta, including the aortic arch, thoracic, abdominal, or ileal areas.

Mouse aortic sinus lesions were characterized according to severity as previously described $(46,47)$ and classified into 3 groups: (a) early lesions containing only foam cells; (b) moderate lesions consisting primarily of macrophage foam cells and some smooth muscle cells in the intima and cap; and (c) advanced lesions containing large extracellular cholesterol clefts or lipid cores and exhibiting disruption of the coherence of the media and thick layers of fibrous connective tissue. The number of lesions of each type was quantified for each genotype and sex, and the lesion distribution was expressed as a percentage of total lesions counted in each group $(n=21)$.

Staining. Immunostaining for macrophage MOMA-2 (Rat IgG2b; Serotec) and $\alpha$-SMA (DakoCytomation) and cytostaining with oil red $\mathrm{O}$, $\mathrm{H} \& \mathrm{E}$, picrosirius red, and Movat's stains were performed as we previously described $(41,44,45)$. Immunostaining and oil red O lipid staining were quantified using IP Lab Spectrum image analysis software and expressed as a percentage of lesion area.

Electron microscopy. Hearts were postfixed overnight in $2 \%$ glutaraldehyde in $0.1 \mathrm{M}$ sodium cacodylate buffer, $\mathrm{pH} 7.4$ at $4^{\circ} \mathrm{C}$, rinsed in cacodylate buffer, and treated with $1 \%$ osmium tetroxide in cacodylate buffer for 1 hour at room temperature. The samples were rinsed in buffer, then in distilled water, and stained en bloc in $2 \%$ aqueous uranyl acetate for 1 hour. Samples were then rinsed in distilled water and dehydrated through a graded

series of ethanol to $100 \%$. Samples were infiltrated overnight on a shaker in a 1:1 solution of Epon-812 resin: $100 \%$ ethanol at room temperature. Following further infiltration in 100\% Epon-812 (Electron Microscopy Sciences), samples were embedded in fresh Epon- 812 overnight at $60^{\circ} \mathrm{C}$. Thin sections were cut on a Reichert Ultracut E ultramicrotome through the aortic sinus, collected onto formvar-coated slot grids, poststained with uranyl acetate and lead citrate, and viewed in a Philips CM 10 transmission electron microscope at $80 \mathrm{kV}$.

Statistics. Statistical analysis was performed with 1-way ANOVA for multiple group comparisons using SigmaStat software. A $P$ value of less than 0.05 was considered significant. All data are presented as the mean \pm SD.

\section{Acknowledgments}

This work was supported by NIH grants HL45098 (M.W. Freeman) and AG20255 (K.J. Moore) and by the Ellison Foundation (K.J. Moore).

Received for publication November 30, 2004, and accepted in revised form April 26, 2005.

Address correspondence to: Mason W. Freeman, Lipid Metabolism Unit, Massachusetts General Hospital, 55 Fruit Street, GRJ1328, Boston, Massachusetts 02114, USA. Phone: (617) 726-5906; Fax: (617) 726-2879; E-mail: freeman@molbio.mgh.harvard.edu.

Kathryn J. Moore and Vidya V. Kunjathoor contributed equally to this work.

1. Endemann, G., et al. 1993. CD36 is a receptor for oxidized low density lipoprotein. J. Biol. Chem. 268:11811-11816.

2. Brown, M.S., Goldstein, J.L., Krieger, M., Ho, Y.K. and Anderson, R.G. 1979. Reversible accumulation of cholesteryl esters in macrophages incubated with acetylated lipoproteins. J. Cell Biol. 82:597-613.

3. Brown, M.S., Basu, S.K., Falck, J.R., Ho, Y.K., and Goldstein, J.L. 1980. The scavenger cell pathway for lipoprotein degradation: specificity of the binding site that mediates the uptake of negatively-charged LDL by macrophages. J. Supramol. Struct. 13:67-81.

4. Matsumoto, A., et al. 1990. Human macrophage scavenger receptors: primary structure, expression, and localization in atherosclerotic lesions. Proc. Natl. Acad. Sci. U. S. A. 87:9133-9137.

5. de Winther, M.P., et al. 1999. Scavenger receptor deficiency leads to more complex atherosclerotic lesions in APOE3Leiden transgenic mice. Atherosclerosis. 144:315-321.

6. Sakaguchi, H., et al. 1998. Role of macrophage scavenger receptors in diet-induced atherosclerosis in mice. Lab. Invest. 78:423-434.

7. Babaev, V.R., et al. 2000. Reduced atherosclerotic lesions in mice deficient for total or macrophagespecific expression of scavenger receptor-A. Arterioscler. Thromb. Vasc. Biol. 20:2593-2599.

8. Febbraio, M., et al. 2000. Targeted disruption of the class B scavenger receptor CD36 protects against atherosclerotic lesion development in mice. J. Clin. Invest. 105:1049-1056.

9. Suzuki, H., et al. 1997. A role for macrophage scavenger receptors in atherosclerosis and susceptibility to infection. Nature. 386:292-296.

10. Williams, K.J., and Tabas, I. 1995. The response-toretention hypothesis of early atherogenesis. Arterioscler. Thromb. Vasc. Biol. 15:551-561.

11. Skalen, K., et al. 2002. Subendothelial retention of atherogenic lipoproteins in early atherosclerosis. Nature. 417:750-754.

12. Kruth, H.S. 2002. Sequestration of aggregated lowdensity lipoproteins by macrophages. Curr. Opin.
Lipidol. 13:483-488.

13. Kruth, H.S., et al. 2005. Macropinocytosis is the endocytic pathway that mediates macrophage foam cell formation with native LDL. J. Biol. Chem. 280:2352-2360.

14. Onitiri, A.C., et al. 1976. Lipoprotein concentrations in serum and in biopsy samples of arterial intima: a quantitive comparison. Atherosclerosis. 23:513-519.

15. Smith, E.B., and Ashall, C. 1983. Low-density lipoprotein concentration in interstitial fluid from human atherosclerotic lesions. Relation to theories of endothelial damage and lipoprotein binding. Biochim. Biophys. Acta. 754:249-257.

16. Kunjathoor, V.V., et al. 2002. Scavenger receptors class A-I/II and CD36 are the principal receptors responsible for the uptake of modified low density lipoprotein leading to lipid loading in macrophages. J. Biol. Chem. 277:49982-49988.

17. Van Eck, M., et al. 2000. Effect of human scavenger receptor class A overexpression in bone marrowderived cells on cholesterol levels and atherosclerosis in apoE-deficient mice. Arterioscler. Thromb. Vasc. Biol. 20:2600-2606.

18. Wolle, S., Via, D.P., Chan, L., Cornicelli, J.A., and Bisgaier, C.L. 1995. Hepatic overexpression of bovine scavenger receptor type I in transgenic mice prevents diet-induced hyperbetalipoproteinemia. J. Clin. Invest. 96:260-272.

19. Medeiros, L.A., et al. 2004. Fibrillar amyloid protein present in atheroma activates CD36 signal transduction. J. Biol. Chem. 279:10643-10648.

20. Moore, K.J., et al. 2002. A CD36-initiated signaling cascade mediates inflammatory effects of betaamyloid. J. Biol. Chem. 277:47373-47379.

21. El Khoury, J.B., et al. 2003. CD36 mediates the innate host response to beta-amyloid. J. Exp. Med. 197:1657-1666.

22. Kruth, H.S. 2001. Macrophage foam cells and atherosclerosis. Front. Biosci. 6:D429-D455.

23. Kruth, H.S., Huang, W., Ishii, I., and Zhang, W.Y. 2002. Macrophage foam cell formation with native low density lipoprotein. J. Biol. Chem. 277:34573-34580.

24. Zalewski, A., and Macphee, C. 2005. Role of lipoprotein-associated phospholipase A2 in atherosclerosis: biology, epidemiology, and possible therapeutic target. Arterioscler. Thromb. Vasc. Biol. 25:923-931.

25. Klimov, A.N., et al. 1985. Lipoprotein-antibody immune complexes. Their catabolism and role in foam cell formation. Atherosclerosis. 58:1-15.

26. Griffith, R.L., Virella, G.T., Stevenson, H.C., and Lopes-Virella, M.F. 1988. Low density lipoprotein metabolism by human macrophages activated with low density lipoprotein immune complexes. A possible mechanism of foam cell formation. J. Exp. Med. 168:1041-1059.

27. Llorente-Cortes, V., Martinez-Gonzalez, J., and Badimon, L. 2000. LDL receptor-related protein mediates uptake of aggregated LDL in human vascular smooth muscle cells. Arterioscler. Thromb. Vasc. Biol. 20:1572-1579.

28. Morita, S.Y., et al. 2004. Ceramide in lipid particles enhances heparan sulfate proteoglycan and low density lipoprotein receptor-related proteinmediated uptake by macrophages. J. Biol. Chem. 279:24355-24361.

29. Freeman, M., et al. 1991. Expression of type I and type II bovine scavenger receptors in Chinese hamster ovary cells: lipid droplet accumulation and nonreciprocal cross competition by acetylated and oxidized low density lipoprotein. Proc. Natl. Acad. Sci.U. S. A. 88:4931-4935.

30. Rohrer, L., Freeman, M., Kodama, T., Penman, M., and Krieger, M. 1990. Coiled-coil fibrous domains mediate ligand binding by macrophage scavenger receptor type II. Nature. 343:570-572.

31. Salvayre, R., Auge, N., Benoist, H., and NegreSalvayre, A. 2002. Oxidized low-density lipoprotein-induced apoptosis. Biochim. Biophys. Acta. 1585:213-221.

32. Febbraio, M., Guy, E., and Silverstein, R.L. 2004. Stem cell transplantation reveals that absence of macrophage CD36 is protective against atheroscle- 
rosis. Arterioscler. Thromb. Vasc. Biol. 24:2333-2338.

33. Reardon, C.A., Blachowicz, L., Lukens, J., Nissenbaum, M., and Getz, G.S. 2003. Genetic background selectively influences innominate artery atherosclerosis: immune system deficiency as a probe. Arterioscler. Thromb. Vasc. Biol. 23:1449-1454.

34. Dansky, H.M., et al. 1999. Genetic background determines the extent of atherosclerosis in apoEdeficient mice. Arterioscler. Thromb. Vasc. Biol. 19:1960-1968.

35. Zhao, Z., et al. 2005. Low-density lipoprotein from apolipoprotein E-deficient mice induces macrophage lipid accumulation in a CD36 and scavenger receptor class A-dependent manner. Arterioscler Thromb. Vasc. Biol. 25:168-173.

36. Whitman, S.C., Rateri, D.L., Szilvassy, S.J., Cornicelli, J.A., and Daugherty, A. 2002. Macrophagespecific expression of class A scavenger receptors in LDL receptor(-/-) mice decreases atherosclerosis and changes spleen morphology. J. Lipid Res. 43:1201-1208.

37. De Winther, M.P., Gijbels, M.J., Van Dijk, K.W., Havekes, L.M., and Hofker, M.H. 2000. Transgenic mouse models to study the role of the macrophage scavenger receptor class A in atherosclerosis. Int. J. Tissue React. 22:85-91.

38. Herijgers, N., et al. 2000. Effect of human scavenger receptor class A overexpression in bone marrow-derived cells on lipoprotein metabolism and atherosclerosis in low density lipoprotein receptor knockout mice. J. Lipid Res. 41:1402-1409.

39. Teupser, D., et al. 1999. Scavenger receptor activity is increased in macrophages from rabbits with low atherosclerotic response: studies in normocholesterolemic high and low atherosclerotic response rabbits. Arterioscler. Thromb. Vasc. Biol. 19:1299-1305.

40. Friedman, G., et al. 1997. Scavenger receptor activity and expression of apolipoprotein $\mathrm{E}$ mRNA in monocyte-derived macrophages of young and old healthy men. Atherosclerosis. 128:67-73.

41. Bjorkbacka, H., et al. 2004. Reduced atherosclerosis in MyD88-null mice links elevated serum cholesterol levels to activation of innate immunity signaling pathways. Nat. Med. 10:416-421.

42. Moore, K.J., et al. 2001. The role of PPAR-gamma in macrophage differentiation and cholesterol uptake. Nat. Med. 7:41-47.

43. Zhang, W.Y., Gaynor, P.M., and Kruth, H.S. 1997. Aggregated low density lipoprotein induces and enters surface-connected compartments of human monocyte-macrophages. Uptake occurs independently of the low density lipoprotein receptor. J. Biol. Chem. 272:31700-31706.

44. Kunjathoor, V.V., Wilson, D.L., and LeBoeuf, R.C. 1996. Increased atherosclerosis in streptozotocininduced diabetic mice. J. Clin. Invest. 97:1767-1773.

45. Kunjathoor, V.V., Chiu, D.S., O’Brien, K.D., and LeBoeuf, R.C. 2002. Accumulation of biglycan and perlecan, but not versican, in lesions of murine models of atherosclerosis. Arterioscler. Thromb. Vasc. Biol. 22:462-468.

46. van Vlijmen, B.J., et al. 1994. Diet-induced hyperlipoproteinemia and atherosclerosis in apolipoprotein E3-Leiden transgenic mice. J. Clin. Invest. 93:1403-1410.

47. Kanters, E., et al. 2003. Inhibition of NF-kappaB activation in macrophages increases atherosclerosis in LDL receptor-deficient mice. J. Clin. Invest. 112:1176-1185. doi:10.1172/JCI200318580. 